\title{
BMJ Open Consensus statement: loneliness in older adults, the 21 st century social determinant of health?
}

\section{Thomas Prohaska, ${ }^{1}$ Vanessa Burholt, ${ }^{2,3}$ Annette Burns, ${ }^{4,5}$ Jeannette Golden, ${ }^{6}$ Louise Hawkley, ${ }^{7}$ Brian Lawlor, ${ }^{8}$ Gerard Leavey (1) , Jim Lubben, ${ }^{5,10}$ Roger O'Sullivan (D) , ${ }^{4,5}$ Carla Perissinotto, ${ }^{11}$ Theo van Tilburg, ${ }^{12}$ Mark Tully, ${ }^{13}$ Christina Victor, ${ }^{14}$ Linda Fried ${ }^{15}$}

To cite: Prohaska T, Burholt V, Burns A, et al. Consensus statement: Ioneliness in older adults, the 21 st century social determinant of health? BMJ Open 2020;10:e034967. doi:10.1136/ bmjopen-2019-034967

- Prepublication history for this paper is available online. To view these files, please visit the journal online (http://dx.doi. org/10.1136/bmjopen-2019034967).

Received 13 October 2019 Revised 20 April 2020 Accepted 02 July 2020
Check for updates

(C) Author(s) (or their employer(s)) 2020. Re-use permitted under CC BY-NC. No commercial re-use. See rights and permissions. Published by BMJ.

For numbered affiliations see end of article.

Correspondence to Professor Roger 0'Sullivan; roger.osullivan@publichealth.ie

\section{ABSTRACT}

Objective The purpose of this consensus statement is to determine the state of the field of loneliness among older people, highlighting key issues for researchers, policymakers and those designing services and interventions.

Methods In December 2018, an international meeting on Ioneliness was held in Belfast with leaders from across the USA and Europe. A summary of the conclusions reached at this event is presented following a consensusbuilding exercise conducted both during this event after each presentation as well as after the event through the drafting, reviewing and agreement of this statement by all authors for over 6 months.

Results This meeting resulted in an agreement to produce a consensus statement on key issues including definitions of loneliness, measurement, antecedents, consequences and interventions.

Discussion There has been an exponential growth in research on loneliness among older adults. However, differing measurements and definitions of loneliness mean the incidence and prevalence, associated risk factors and health consequences are often conflicting or confusing especially for those developing policy and services.

In December 2018, a group of international researchers, practitioners and policymakers working in the area of ageing met as part of a 3-day symposium held in Belfast, Northern Ireland to discuss loneliness, its impacts and appropriate interventions. ${ }^{1-15}$ It is encouraging that there has been an exponential growth in research on loneliness and social isolation among older adults of late, in recognition of the significance of loneliness as an adverse experience in older age. However, limitations persist in the evidence base, in relation to impacts, risk factors, assessment and especially interventions. The objective of the Belfast meeting was to determine the state of the field of loneliness among older people, highlighting best practices, evidence and key research gaps. The following consensus statement emerged from these discussions in relation to the current status of policy, practice and especially research on loneliness.

\section{CONTEXT}

It seems there have never been so many ways to connect with people, yet the fear of loneliness is increasingly capturing public attention, driving the issue further up policy agendas across the world. ${ }^{16}$ For example, in the UK, 2018 saw the launch of a loneliness strategy ${ }^{17}$ and a loneliness minister was appointed. In the USA, the National Academies of Sciences, Engineering, and Medicine have formed a committee to examine how social isolation and loneliness impact health outcomes in older adults, its report released in February of $2020{ }^{18}$ The AARP in the USA and the Campaign to End Loneliness in the UK have established awareness raising work and visibility in this area. Campaigns are an important necessary step to raise awareness to effectively address the stigma of loneliness but are not sufficient especially for the development of effective interventions.

With growing concern about rates and consequences of loneliness in civic society, there is also an increasing body of research on loneliness and social isolation among older adults, especially in high-income countries (HICs). However, there are significant gaps in our understanding of the 'true rates' of loneliness within and across countries, the drivers of loneliness in different populations and sub-groups, its impact on health and wellbeing, and a lack of high quality evidence on effective solutions. In low/middle-income countries (LMICs), research to underpin the allocation of resources to meet medical needs, and/or to secure adequate food and housing in later life has been given greater priority than studies on loneliness. ${ }^{19}$ In summary, 
evidence to support appropriate action in addressing loneliness is urgently needed. However, a number of building blocks are required in relation to definitions, measurement, antecedents, consequences and ultimately effective interventions. ${ }^{1820}$

\section{METHODS}

At our 3-day event in December 2018, AB took detailed notes during all presentations and discussions. Following the event, $\mathrm{AB}$ synthesised these notes to produce a single document detailing all topics on which some consensus was reached at the event in relation to loneliness in older adults that is, multiple authors had supported a statement or argument. This document was then sectioned into issues related to: definition and types of loneliness; measurement of loneliness; antecedents of loneliness; consequences of loneliness; and interventions. This document was shared with ROS and TP to refine further before being shared with all authors to check consensus. Following each circulation, any issues raised by authors were synthesised with feedback requested from all authors again prior to a new draft based on these agreed changes being circulated. Following a 6-month period and the circulation of multiple drafts, all authors signed off on a final consensus statement (the content of this communication) which represented the views of all and addressed all issues raised during the process to the satisfaction of all.

\section{DEFINITIONS}

Loneliness has been defined in many ways and an agreed definition of loneliness remains elusive, but it is acknowledged as distinct from social isolation and social exclusion. ${ }^{10}$ Loneliness is a subjective negative experience that results from inadequate meaningful connections, where 'inadequate' refers to the discrepancy or unmet need between an individual's preferred and actual experience. ${ }^{321}$ Loneliness has been described in a range of different domains and experienced as a sense of inadequate social connection to:

- An intimate other person.

- Family and friends.

- Community life, collective identity and roles bringing connections to the broader society with meaning and purpose.

Different domains of loneliness are reflected in research that distinguishes between emotional and social loneliness, where emotional loneliness is characterised by the absence of an intimate connection and social loneliness is characterised by the absence of contact and engagement with a broader network of friends, neighbours and colleagues. ${ }^{22}{ }^{23}$ Others have distinguished between loneliness that is intimate, relational (marked by the perceived lack of close friends/confidants), and collective (characterised by a perceived lack of a sense of belonging or group identity). ${ }^{24}$ Still others discuss existential loneliness. ${ }^{25}$
To date, the range of definitions of loneliness has been useful for drawing attention to the issue but not sufficient for advancing the field to explain, for example, the intensity, frequency and duration of loneliness. Loneliness can be acute (ie, transient) or chronic (ie, enduring), and it can be mild to severe in its intensity. Moreover, it can stem from a variety of antecedents, and each precursor may require a unique 'solution'. Researchers, policymakers and practitioners all tend to define and discuss loneliness differently which can create confusion as to what is meant as well as what actions to take for policy, services and society. To deliver effective policy and practice requires a more nuanced understanding of the complexity of loneliness (eg, the different pathways, types and ways of addressing loneliness) which, while not considered a medical condition, can have an impact on health.

Further theoretical and empirical work is needed to adequately conceptualise the complexity of loneliness, and to distinguish its various domains and types and frequencies. Unfortunately, the focus has tended to be on social loneliness with relative neglect of other types of loneliness. In particular, there is a need to develop a unified language and definition(s) to facilitate the discussion of loneliness, its evidence and mechanisms for its effects, and to develop theoretical frameworks that situate loneliness and its antecedents and consequences in a global social context. Doing so would also permit accurate comparisons of global loneliness trends, and could accelerate the development and dissemination of interventions across countries.

\section{MEASUREMENT}

Directly connected to definitions, standardised and validated measurement of loneliness is crucial. Currently, different studies use a mixture of scales (which assess frequency only) and single-item measures, while some reviews have further combined these with aspects such as living alone and marital status under the umbrella term of isolation/loneliness, leading to an ambiguous and unreliable evidence base.

The most widelyused validated loneliness scales are:

- UCLA Loneliness Scale ${ }^{26}$; Revised UCLA Loneliness Scale, version $3^{27}$; UCLA three-item Loneliness Scale. ${ }^{28}$

- the De Jong Gierveld 11-item or six-item Loneliness Scale. ${ }^{22} 2930$

The UCLA Loneliness Scale is intended to assess loneliness as a unitary construct; dimensions of the loneliness experience have been identified in factor analyses but they are subsumed in a higher level loneliness construct. In contrast, the De Jong Gierveld Scale assesses overall as well as emotional and social loneliness through its subscales. Though less widely used, the Social and Emotional Loneliness Scale for Adults ${ }^{23}$ also distinguishes between social and emotional loneliness and further distinguishes two domains of emotional loneliness-family and romantic. 
In addition to the original 37-item measure, a revised 15 -item version is also used. ${ }^{31}$

While not always co-occurring, there is an association and overlap between social isolation and loneliness. ${ }^{1} 10$ Common measures of social isolation include the sixitem Lubben Social Network Scale ${ }^{32} 33$ and the four-item Berkman-Syme Social Network Index. ${ }^{34}{ }^{35}$ To date there has been no consensus statement on social isolation in terms of definitions, measurement and scales; however, many of the points made in the current paper in relation to loneliness are also relevant. ${ }^{36}$

The symposium participants did not explore or compare measures or their relative utility. However, it was recognised that a common set of validated measures of loneliness is needed in order to examine findings across research and interventions. The systematic inclusion of a harmonised set of covariates, demographic factors and antecedent or predictor measures would also facilitate meta-analyses and evidence-based reviews. A selection of scales currently used to assess both loneliness and isolation is available here (https://www.publichealth.ie/ ILINK).

A consensus was reached that validated brief versions of all measures should be made available and promoted both for clinical and non-clinical settings to avoid the ad hoc editing of standardised measures, rendering findings often invalid, misleading or confusing (this conclusion of not using measures ad hoc is also supported by National Academies of Sciences, Engineering, and Medicine). ${ }^{18}$ Standardised measures of loneliness must be used in order to build a valid evidence base to help inform policy, practice and services. It is also recognised that these scales have been developed in HIC/individualistic cultures and thus require validation in LMIC, and collectivist cultures, where they may be not be as relevant or capture all dimensions.

\section{ANTECEDENTS}

The determinants of loneliness are varied and complex. Understanding the complexity of the pathways into and out of loneliness requires research across a range of populations and subgroups, including longitudinal studies. A better understanding of root causes, pathways and trajectories of loneliness should in turn facilitate individual and community strategies, interventions, as well as the targeted matching of interventions.

Personal level characteristics (eg, gender, marital status, socioeconomic status) are often included as antecedents to loneliness in research, but there is less focus on the role of environmental and structural factors. The role of environments appears important to the field and can be both enabling and disabling in terms of loneliness, like many other public issues. At the community/ neighbourhood level, it is important to consider the risk factors that can contribute to loneliness such as community safety, design of the built environment, community and neighbourhood design, civic spaces, transportation, community-engagement opportunities, and access to activities and amenities within the local area. ${ }^{21}$

At a societal level, we have limited evidence on the structural and cultural changes or societal forces that may foster loneliness and contribute to social determinants of health in the 21st century (ie, public policies, public discourse, and dominant political and economic ideologies that influence the structure of society and ultimately our health and well-being). ${ }^{37}$ In Western and capitalist economies, socioeconomic stresses and inequalities, automation, changing work, family, household and community structures, and the increasing use of social media and the internet for services and goods may be contributing to an erosion of communities and loss of connections, meaning and purpose. However, the evidence on the impacts of societal factors on loneliness is limited. The perceptions and expectations of today's society around ageing, older people, ageism and loneliness also need to be untangled. ${ }^{2}$ Evidence to date suggests that solutions for loneliness will need to be developed at population as well as individual levels. ${ }^{11}$

While demographic ageing means loneliness is likely to increase numerically, the majority of older adults are not chronically lonely and evidence indicates that loneliness is also experienced by other age groups, especially young adults where levels are even higher than in older adults. ${ }^{20}$ Although not proportionally increasing in older adults, ${ }^{38-40}$ loneliness has risen up the agenda. Whether this is connected to a broader sense of dissatisfaction, disconnection and fragmentation in current society which may be expressing itself at present via an attachment to the concept of loneliness remains unclear.

\section{CONSEQUENCES}

The consequences of loneliness on health and wellbeing can be profound. While there is inadequate causal evidence, the associations with poor health and wellbeing have been established. Evidence suggests associations with mental health, with evidence especially strong for depression, ${ }^{41}$ non-communicable diseases (eg, cardiovascular disease) ${ }^{42}$ health behaviours (eg, physical activity), ${ }^{43}$ stress, sleep, ${ }^{44}{ }^{45}$ cognition $^{46}$ and premature mortality. ${ }^{47}$ Paradoxically, there is a concern that chronic loneliness can adversely affect one's ability to connect with others positively and to engage in interventions that could decrease loneliness.

Further work is required to strengthen the evidence for a causal link between loneliness and health outcomes. Moreover, additional research is needed to determine how the duration and frequency of loneliness contribute to health outcomes, and whether temporal effects differ across outcomes (eg, emotional vs cardiovascular status). Beyond health, the social consequences of loneliness also remain unclear. There is a need for more robust research using standardised validated measures, adjusted for potential confounders, mediators and moderators to 
assess if currently reported associations are independently predicted by loneliness and if so, to what degree. ${ }^{48}$

\section{INTERVENTIONS}

In response to the needs of older people and the issue of loneliness, the field of work in delivering programmes and policy is moving faster than the research community. This important work by charities, voluntary organisations and community partners can only benefit from the availability of a more robust evidence base. ${ }^{49}$ The current evidence base for many interventions is characterised by low-quality trials, small samples, a lack of theoretical frameworks or understanding of loneliness, diverse or undefined target groups, mixed measures of loneliness and short follow-up periods to assess longer term impact. While we recommend appropriate use of the validated widely used measures described above, we also acknowledge that minimal attention has been directed toward determining the optimal intensity, duration and frequency of the therapeutic elements of loneliness interventions and further validated established outcomes are therefore needed.

As well as the research evidence and alignment, political and civic leadership is needed to plan how best to incorporate loneliness interventions for an ageing population. Use of a public health approach, incorporating multiple perspectives and tailored for the needs of individuals may help prevent loneliness and yield societal benefits. Beyond the evaluation of existing programmes, better evidence on alternative interventions is needed. Strategies for generating evidence-based interventions should include diverse populations and cultural settings and not be limited to clinical or other relatively accessible groups. Interventions incorporating preventive or therapeutic elements as identified in already successful interventions are also required. Additionally, an assessment of the public health impact of community-based loneliness interventions should be determined, including the reach, effectiveness, adoption, implementation and maintenance of such programmes. ${ }^{50}$ While not addressed adequately in the symposium, more attention towards determining the utility of primary, secondary and tertiary prevention is recommended. Potential examples include, for primary prevention, attention to design of the built and social environment to understand its impact on the ability to connect and prevent loneliness and design effective solutions and programmes, whether on one-on-one, social network or collective social good levels. For people of all ages, this could well involve community engagement in shared roles with meaning and benefit to the community. Secondary prevention could involve screening for those at risk-such as those who have newly retired or been widowed - whether at community or clinical levels, and identifying effective interventions to help prevent loneliness in this at-risk group. Tertiary prevention could involve recognition of those who are acutely or chronically lonely, with or without manifesting its sequelae, and referral to programmes for skill remediation, therapy and/or connection, as indicated.

Overall interventions must be tailored and matched to specific root causes of loneliness in the individual, supporting personalised solutions whereby the individual is met in their own context/situation. While inevitably more complex to implement and evaluate, current evidence indicates that this tailored approach is a necessity.

\section{A WAY FORWARD}

We need to more fully understand and address the antecedents and consequences of loneliness in later life. Research and evidence gaps have been noted throughout this paper and we recommend that research strategies are linked to complement and inform policy and practice interventions on loneliness. Future research is needed to help expand our understanding of loneliness, antecedents and consequences across the life course and in different groups such as young people, migrants, lesbian, gay, bisexual and transgender community, and other minority groups, as well as country/cultural differences and diverse health domains including the impact of enduring long-term loneliness. The consensus group discussed strategies on how these should be addressed, including the establishment of the International Loneliness and social Isolation research Network as a vehicle to facilitate knowledge exchange and learning. The research, policy and practice community, and ultimately civic society can benefit from a greater pooling of expertise and knowledge exchange in this area to ensure that we all play our part in addressing loneliness.

\section{LIMITATIONS}

This statement is limited by its lack of data or representatives from LMICs and also by its broad focus on Englishspeaking countries with only one author from a country where English is not the first language represented (the Netherlands). The representatives of this group have however worked in LMICs and with ethnic minority groups from these countries. As a group, we acknowledge the lack of research from LMICs on prevalence, pathways and cultural differences in measurement.

\section{Author affiliations}

${ }^{1}$ College of Health and Human Services, George Mason University, Fairfax, Virginia, USA

${ }^{2}$ School of Nursing/School of Population Health, The University of Auckland, Auckland, New Zealand

${ }^{3}$ College of Human and Health Sciences, Swansea University, Swansea, UK ${ }^{4}$ Institute of Public Health in Ireland, Dublin, Ireland

${ }^{5}$ Bamford Centre for Mental Health and Well Being, Ulster University, Coleraine, UK ${ }^{6}$ Mercer's Institute for Successful Ageing, Saint James's Hospital, Dublin, Ireland ${ }^{7}$ Academic Research Centers, NORC at the University of Chicago, Chicago, Illinois, USA

${ }^{8}$ Global Brain Health Institute, Trinity College, Dublin, Ireland

${ }^{9}$ School of Social Work, Boston College, Chestnut Hill, Massachusetts, USA 
${ }^{10}$ Luskin School of Public Affairs, University of California, Los Angeles, California, USA

${ }^{11}$ Division of Geriatrics, Department of Medicine, University of California, San

Francisco, California, USA

${ }^{12}$ Department of Sociology, Faculty of Social Sciences, University Amsterdam, Amsterdam, The Netherlands

${ }^{13}$ School of Health Sciences, Ulster University, Coleraine, UK

${ }^{14}$ College of Health and Life Sciences, Brunel University, London, UK

${ }^{15}$ Mailman School of Public Health, Columbia University, New York, New York, USA

Acknowledgements We would like to thank all the contributors (practitioners, policymakers and researchers) to the symposium for their presentations and for the insightful discussion that took place over the 3 days.

Contributors TP and LF led on the drafting of this manuscript. All other listed authors (VB, AB, JG, LH, BL, GL, JL, R'OS, CP, TvT, MT and CV) had made substantial contributions to the design and content of this paper during the December meeting and/or subsequently to this meeting during the drafting and development of this statement. All authors (TP, VB, AB, JG, LH, BL, GL, JL, R'OS, CP, TVT, MT, CV and LF) also commented on drafts and assisted in revising for important intellectual content before providing final approval for this version. All listed authors (TP, VB, $\mathrm{AB}, \mathrm{JG}, \mathrm{LH}, \mathrm{BL}, \mathrm{GL}, \mathrm{JL}, \mathrm{R}^{\prime} \mathrm{OS}, \mathrm{CP}, \mathrm{TVT}, \mathrm{MT}, \mathrm{CV}$ and LF) have agreed to be accountable for all aspects of the work in relation to its accuracy, integrity, and the appropriate investigation and resolution of all associated questions.

Funding The authors have not declared a specific grant for this research from any funding agency in the public, commercial or not-for-profit sectors.

Competing interests None declared.

Patient consent for publication Not required.

Provenance and peer review Not commissioned; externally peer reviewed.

Open access This is an open access article distributed in accordance with the Creative Commons Attribution Non Commercial (CC BY-NC 4.0) license, which permits others to distribute, remix, adapt, build upon this work non-commercially, and license their derivative works on different terms, provided the original work is properly cited, appropriate credit is given, any changes made indicated, and the use is non-commercial. See: http://creativecommons.org/licenses/by-nc/4.0/.

\section{ORCID iDs}

Gerard Leavey http://orcid.org/0000-0001-8411-8919

Roger 0'Sullivan http://orcid.org/0000-0001-6433-8404

\section{REFERENCES}

1 Burholt V. The complexity of loneliness in later life: addressing the issues. loneliness in later life: interventions - what works?, Belfast, Northern Ireland. Available: https://publichealth.ie/ilink/ [Accessed 5-7th Dec 2018].

2 Fried L. Designing a new social infrastructure for 21 st century needs. Loneliness in Later Life: Interventions - what works? 5-7th December 2018, Belfast, Northern Ireland. Available: https://publichealth.ie/ilink/

3 Fried L, Prohaska T, Burholt V, et al. A unified approach to loneliness. Lancet 2020;395:114.

4 Golden J. A clinical experience of loneliness - reflections on learning loneliness in later life: interventions - what works? 5-7th December 2018, Belfast, Northern Ireland. Available: https://publichealth.ie/ilink/

5 Leavey G. Loneliness in Ireland and the Irish Migrants. Loneliness in Later Life: Interventions - what works? 5-7th December 2018, Belfast, Northern Ireland. Available: https://publichealth.ie/ilink/

6 Lubben J. Isolation and Loneliness - a US Perspective. Loneliness in Later Life: Interventions - what works? 5-7th December 2018, Belfast, Northern Ireland. Available: https://publichealth.ie/ilink/

7 Lynch E. Commissioner for Older People: Loneliness in Later Life. Loneliness in Later Life: Interventions - what works? 5-7th December 2018, Belfast, Northern Ireland. Available: https://publichealth.ie/ilink/

8 Moynihan S. ALONE: A national response to loneliness and improving the health and wellbeing of older and vulnerable adults in Ireland. Loneliness in Later Life: Interventions - what works? 5-7th December 2018, Belfast, Northern Ireland. Available: https:// publichealth.ie/ilink/

9 Murphy F. Campaign to end loneliness: learning for research, policy and practice. Loneliness in Later Life: Interventions - what works? 5-7th December 2018, Belfast, Northern Ireland. Available: https:// publichealth.ie/ilink/
10 Perissinotto C. The Role of the Health Professional in Loneliness Assessments. Loneliness in Later Life: Interventions - what works? 5-7th December 2018, Belfast, Northern Ireland. Available: https:// publichealth.ie/ilink/

11 Prohaska T. A public health approach to loneliness? Loneliness in Later Life: Interventions - what works? 5-7th December 2018, Belfast, Northern Ireland. Available: https://publichealth.ie/ilink/

12 Reid S. Public Health Agency: Loneliness in later life - Public health responses. Loneliness in Later Life: Interventions - what works? 5-7th December 2018, Belfast, Northern Ireland. Available: https:// publichealth.ie/ilink/

13 Sheridan B. Men's Sheds: A model for addressing loneliness, isolation and improving health and wellbeing among men. Loneliness in Later Life: Interventions - what works? 5-7th December 2018 , Belfast, Northern Ireland. Available: https://publichealth.ie/ilink/

14 van Tilburg TG. Loneliness in the Netherlands. Loneliness in Later Life: Interventions - what works? 5-7th December 2018, Belfast, Northern Ireland. Available: https://publichealth.ie/ilink/

15 Victor C. Loneliness - a UK Perspective - what we know, what we think we know and what we don't know. Loneliness in Later Life: Interventions - what works? 5-7th December 2018, Belfast, Northern Ireland. Available: https://publichealth.ie/ilink/

16 O'Sullivan R. The age of loneliness? Annual public health lecture. Féile an Phobail. 6th August 2019. Belfast. Northern Ireland

17 HM Government. A connected Society: a strategy for tackling loneliness - laying the foundations for change. Department for Digital, Culture, Media and Sport, London, 2018. Available: https:// www.gov.uk/government/publications/a-connected-society-astrategy-for-tackling-loneliness

18 National Academies of Sciences, Engineering and Medicine. Social isolation and loneliness in older adults: opportunities for the health care system. Washington, DC: The National Academies Press, 2020.

19 Burholt V, Scharf T. Critical social gerontology and rural ageing. In: Skinner M, Winterton R, Walsh K, eds. Rural gerontology: towards critical perspectives on rural ageing. London and New York: Routledge, 2020.

20 Victor C, Mansfield L, Kay T, et al. An overview of reviews: the effectiveness of interventions to address loneliness at all stages of the life-course. what works centre for wellbeing 2018.

21 Perlman D, Peplau LA. Toward a social psychology of loneliness. Pers Relatsh 1981;3:31-56.

22 de Jong-Gierveld J, Kamphuls F. The development of a Rasch-type loneliness scale. Appl Psychol Meas 1985;9:289-99.

23 DiTommaso E, Spinner B. The development and initial validation of the social and emotional loneliness scale for adults (SELSA). Pers Individ Dif 1993;14:127-34.

24 Hawkley LC, Browne MW, Cacioppo JT. How can I connect with thee? Let me count the ways. Psychol Sci 2005;16:798-804.

25 Mayers AM, Khoo S-T, Svartberg M. The Existential loneliness questionnaire: background, development, and preliminary findings. $J$ Clin Psychol 2002;58:1183-93.

26 Russell D, Peplau LA, Cutrona CE. The revised UCLA loneliness scale: concurrent and discriminant validity evidence. J Pers Soc Psychol 1980;39:472-80.

27 Russell DW, Scale UL. UCLA loneliness scale (version 3): reliability, validity, and factor structure. J Pers Assess 1996;66:20-40.

28 Hughes ME, Waite LJ, Hawkley LC, et al. A short scale for measuring loneliness in large surveys: results from two population-based studies. Res Aging 2004;26:655-72.

29 De Jong Gierveld J, Van Tilburg TG. Manual of the loneliness scale. Amsterdam: VU University, 1999.

30 De Jong Gierveld J, Van Tilburg T. The de Jong Gierveld short scales for emotional and social loneliness: tested on data from 7 countries in the un generations and gender surveys. Eur J Ageing 2010;7:121-30

31 DiTommaso E, Brannen-McNulty C, Ross L, et al. Social skills and loneliness in young adults. Pers Individ Dif 2003;35:303-12.

32 Lubben JE, Gironda MW. Measuring Social Networks and Assessing their Benefits. In: Phillipson C, Allan G, Morgan D, eds. Social networks and social exclusion. Hants, England: Ashgate, 2003: 20-49.

33 Lubben J, Blozik E, Gillmann G, et al. Performance of an abbreviated version of the Lubben social network scale among three European community-dwelling older adult populations. Gerontologist 2006;46:503-13.

34 Berkman LF, Syme SL. Social networks, host resistance, and mortality: a nine-year follow-up study of Alameda County residents. Am J Epidemiol 1979;109:186-204.

35 Chang S-C, Glymour M, Cornelis M, et al. Social integration and reduced risk of coronary heart disease in women: the role of lifestyle behaviors. Circ Res 2017;120:1927-37. 
36 Newall NEG, Menec VH. A comparison of different definitions of social isolation using Canadian longitudinal study on aging (CLSA) data. Ageing Soc 2019;15:1-24.

37 Marmot M, Allen J, Goldblatt P, et al. The Marmot review: fair Society, healthy lives. The strategic review of health inequalities in England Post-2010. London: Marmot Review Team, 2010.

38 Hawkley LC, Wroblewski K, Kaiser T, et al. Are U.S. older adults getting lonelier? Age, period, and cohort differences. Psychol Aging 2019;34:1144-57.

39 Victor CR, Scambler SJ, Shah S, et al. Has loneliness amongst older people increased? an investigation into variations between cohorts. Ageing Soc 2002;22:585-97.

40 van Tilburg TG, Aartsen MJ, van der Pas S. Loneliness after divorce: a cohort comparison among Dutch young-old adults. Eur Sociol Rev 2015;31:243-52.

41 Cacioppo JT, Hawkley LC, Thisted RA. Perceived social isolation makes me sad: 5-year cross-lagged analyses of loneliness and depressive symptomatology in the Chicago health, aging, and social relations study. Psychol Aging 2010;25:453-63.

42 Valtorta NK, Kanaan M, Gilbody S, et al. Loneliness and social isolation as risk factors for coronary heart disease and stroke: systematic review and meta-analysis of longitudinal observational studies. Heart 2016;102:1009-16.

43 Pels F, Kleinert J. Loneliness and physical activity: a systematic review. Int Rev Sport Exerc Psychol 2016:9:231-60.

44 Choi H, Irwin MR, Cho HJ. Impact of social isolation on behavioral health in elderly: systematic review. World J Psychiatry 2015;5:432-8.

45 McHugh JE, Lawlor BA. Perceived stress mediates the relationship between emotional loneliness and sleep quality over time in older adults. Br J Health Psychol 2013;18:546-55.

46 Cacioppo JT, Hawkley LC. Perceived social isolation and cognition. Trends Cogn Sci 2009;13:447-54.

47 Holt-Lunstad J, Smith TB, Baker M, et al. Loneliness and social isolation as risk factors for mortality: a meta-analytic review. Perspect Psychol Sci 2015;10:227-37.

48 Burholt V, Winter B, Aartsen M, et al. A critical review and development of a conceptual model of exclusion from social relations for older people. Eur J Ageing 2019:1-17.

49 Harvey B, Walsh K. Loneliness and ageing: Ireland, North and South. Dublin: Institute of Public Health in Ireland, 2016.

50 Glasgow RE, Vogt TM, Boles SM. Evaluating the public health impact of health promotion interventions: the RE-AIM framework. Am J Public Health 1999;89:1322-7. 